\title{
Leishmaniose tegumentar americana associada à AIDS: relato de quatro casos
}

\author{
American cutaneous leishmaniasis associated with \\ HIV/AIDS: report of four clinical cases \\ Raimunda Nonata Ribeiro Sampaio', Cristina Paula Salaro², \\ Paula Resende ${ }^{2}$ e Carmen Déa Ribeiro de Paula ${ }^{2}$
}

\begin{abstract}
Resumo A co-infecção leishmaniose tegumentar americana e AIDS é de relato recente na literatura, observando-se diversidade quanto ao comportamento clínico e imunológico destes pacientes. Relatamos quatro casos acompanhados no Hospital Universitário de Brasília, com diagnóstico de infecção por parasitas do gênero Leishmania e pelo vírus da imunodeficiência humana, ilustrando diferentes apresentações clínicas, evoluções e respostas terapêuticas.
\end{abstract}

Palavras-chaves: Leishmaniose tegumentar americana. AIDS. Aspecto clínico. Terapêutica.

Abstract The co-infection American cutaneous leishmaniasis and AIDS has recently been described in the literature, observing differences between the clinical and immunological behavior of these patients. Four cases are reported here, attended at the Brasilia University Hospital, with diagnoses of infection by Leishmania species and immunodeficiency virus, with a view to illustrating the clinical presentations, course and therapeutic responses.

Key-words: Leishmaniasis. AIDS. Clinical course. Therapeutics.

A leishmaniose tegumentar americana (LTA) é uma protozoose causada por parasitas do gênero Leishmania. Em nosso meio, seu principal agente etiológico é a Leishmania Viannia braziliensis $(L V b)$. Caracteriza-se por apresentar espectro de manifestações clínicas e imunológicas que variam de um pólo anérgico (leishmaniose cutânea difusa) a outro hiperérgico (leishmaniose mucosa), estando portanto - quadro clínico relacionado às características do parasita e às interações que ocorrem entre este e o sistema imunológico do hospedeiro?

A leishmania, além de ser um parasita intracelular, o que dificulta a resposta do hospedeiro, apresenta outros mecanismos de escape imunológico que favorecem sua persistência e multiplicação no organismo, tais como: a) inibição da estimulação de linfócitos Th1, produtores de citocinas como interleucina 2 e interferon gama, responsáveis pela defesa celular; b) diminuição da atividade de células citotóxicas naturais (NK); c) redução da expressão de antígenos do complexo de histocompatibilidade principal classe II que dificulta o seu reconhecimento pelas células do sistema imunológico, e; d) inibição da expressão da óxido nítrico sintetase, o que favorece a sobrevida intracelular do parasito 24510 .

No entanto, a susceptibilidade do indivíduo à infecção depende do tipo de resposta imunocelular que este desenvolve após a inoculação do parasita. Esta resposta varia de acordo com a espécie do parasita, a predisposição genética e o estado de imunossupressão do hospedeiro.Tem sido relatada a ocorrência de LTA em pacientes portadores da síndrome da imunodeficiência adquirida (AIDS). O primeiro caso foi descrito em 1987 em um paciente proveniente do Estado do Rio de Janeiro (Brasil) que apresentou LTA cutâneo-mucosa clinicamente concomitante à infecção

\footnotetext{
1. Serviço de Dermatologia do Hospital Universitário de Brasília, Brasília, DF. 2. Laboratório de Dermatomicologia da Faculdade de Medicina da Universidade de Brasília. Brasília, DF.

Endereço para correspondência: Prof ${ }^{a}$ Raimunda Nonata Ribeiro Sampaio. SHIS QI 25 cj 02 casa 01, 71660-220 Brasília, DF.

Fax: $5561367-3825$

e-mail: rnrsampaio@ hotmail.com

Recebido para publicação em 30/5/2000
} 
pelo $\mathrm{HIV}^{3}$. Nos vinte e cinco casos publicados, até o momento, tem se observado a diversidade clínica, quadros mais graves, disseminação e refratariedade ao tratamento habitual.
Nós relatamos quatro casos que ilustram a concomitância de LTA e AIDS. Esta associação tem implicações clínicas e imunológicas que serão discutidas subseqüentemente.

\section{RELATOS DOS CASOS}

Caso 1: ARS., 26 anos, masculino, solteiro, garimpeiro, natural e procedente de Alta Floresta, MT. Em janeiro de 1995, queixava-se de úlcera em membro inferior direito há 7 meses que fora tratada em sua cidade de origem com $\mathrm{N}$-metil-glucamina, 14mg SbV/kg/dia por 37 dias.

Cinco meses após o tratamento houve surgimento de nova úlcera em membro inferior direito e obstrução nasal com eliminação de crostas. Procurou nosso serviço, onde foram constatadas clinicamente úlceras cutâneas com fundo granuloso, bordas elevadas e infiltradas e infiltração em mucosa nasal, com destruição de septo nasal posterior e hiperemia de orofaringe. A época, apresentava diarréia crônica.

Reação de Montenegro $15 \times 10 \mathrm{~mm}$, esfregaço positivo, cultura para LTA negativa, histologia: infiltrado histiolinfoplasmocitário compatível com LTA. Sorologia para HIV positiva.

Recebeu dose total de pentamidina de $2,4 \mathrm{~g}$ apresentando melhora importante do quadro, retornando à sua cidade de origem.

O paciente não realizou exame de carga viral e não aderiu ao tratamento com medicações antiretrovirais, tendo se evadido do serviço.

Caso 2: WOF, 38 anos, masculino, pardo, solteiro, desempregado, natural de Curuaçu, GO e procedente de Taguatinga, DF. No ano de 1997, relatava que há 14 anos fora portador de LTA cutânea tratada irregularmente com antimonial pentavalente (10mgSbV/ kg/dia) mas obtivera cicatrização completa da lesão. Há um ano apresentou ulceração em mucosa nasal associado à rinorréia, obstrução nasal e epistaxe. Negava outros sintomas respiratórios e febre. Relatava perda de oito quilos em 1 ano. Ao exame, observava-se infiltração, eritema em dorso do nariz e úlcera em mucosa nasal com destruição parcial do septo.

Exames laboratoriais e evolução do caso: a intradermorreação de Montenegro (IDR) era positiva (10x10mm ); o esfregaço a cultura e a inoculação em hamster para leishmania foram positivos e a espécie identificada por anticorpos monoclonais foi Leishmania Viannia braziliensis. O exame histopatológico da mucosa nasal revelava infiltrado linfoplasmohistiocitário com ausência de parasitas. As culturas para bactérias, fungos e micobactérias foram negativas. O hemograma completo, sumário de urina, provas de função hepática, pancreática, renal e o ECG eram normais.

Com este quadro clínico e investigação laboratorial, foi feito o diagnóstico de LTA.

Iniciou o tratamento com stibogluconato de sódio (20mgSbV/kg/dia), quando na sétima dose desenvolveu insuficiência ventricular aguda, sendo suspensa a medicação. Posteriormente, foi introduzida pentamidina $(4 \mathrm{mg} / \mathrm{kg} / \mathrm{dia}$ IM com dose total de $2 \mathrm{~g}$ ) com melhora apenas parcial da lesão.

Diante da falha terapêutica com pentamidina, foi administrado anfotericina $B$ (dose total $2 \mathrm{~g} \mathrm{EV}$ ) com cicatrização completa da lesão. Durante este período foi realizada a sorologia anti-HIV, Elisa e Western-Blott, com resultado positivo. A contagem de células CD4 era de 185 células por $\mathrm{mm}^{3}$, com quantificação da carga viral em 150.000 cópias por ml (em março de 1998). Seis meses após o término do tratamento, houve recidiva parcial da ulceração associado a um quadro respiratório compatível com pneumocistose.

Durante 4 meses recebeu tratamento antiretroviral com AZT, ddl e Indinavir, medicação suspensa por falta de adesão terapêutica.

No momento o paciente está sendo acompanhado pelo serviço de Dermatologia e Infectologia do Hospital Universitário de Brasília (HUB), apresentando infiltração discreta e pequena ulceração em mucosa nasal que permanece inalterada há 2 meses, sob observação.

Caso 3: ABF, 39 anos, feminina, branca, casada, auxiliar de enfermagem, natural de Goianésia, GO e procedente do Gama, DF. Relatava no ano de 1997, que apresentava há 7 anos infiltração e edema em dorso do nariz associado a obstrução nasal, epistaxe e perfuração do septo. Permaneceu sem assistência médica, até que há 2 anos teve o diagnóstico deLTA em outro serviço. Foi tratada com antimonial pentavalente ( $\mathrm{N}$-metil-glucamina $20 \mathrm{mgSbV} / \mathrm{kg} /$ dia EV) durante 20 dias, com melhora parcial do quadro. Há 1 ano e 5 meses procurou nosso serviço por haver piora da lesão, recebeu novo tratamento com antimonial pentavalente a mesma dosagem anteriormente administrada prolongada por 30 dias, sem resposta clínica. Referia perda de 5 quilos no período e sorologia anti-HIV positiva. Negava outros sintomas.

Ao exame, observava-se edema, eritema em dorso e ponta de nariz com ulceração de mucosa nasal, recoberta por crosta melicérica, e destruição parcial do septo.

Exames laboratoriais e evolução do caso: a IDR era de $10 \times 10 \mathrm{~mm}$; o esfregaço e cultura para leishmania foram negativos, a inoculação em hamster foi negativa, a imunofluorescência indireta foi positiva com titulação 1/320 e o exame histopatológico mostrava um infiltrado inflamatório linfoplasmohistiocitário denso com ausência de parasitas. As culturas para bactérias, fungos e micobactérias foram negativas. O hemograma completo, sumário de urina e provas de função hepática, renal e 
amilase se apresentaram normais. A sorologia anti-HIV realizada neste hospital foi reagente, com 1 milhão de cópias RNA viral por ml; a contagem de CD4 era de 152 células por $\mathrm{mm}^{3}$. Diante deste quadro clínico e laboratorial foi feito o diagnóstico de LTA associada ao HIV.

A paciente foi tratada com anfotericina $B$ (dose total $1,7 \mathrm{~g}$ EV), apresentando retenção nitrogenada significativa que resultou na interrupção da droga. Durante a internação, evoluiu com o quadro neurológico de confusão mental e hemiparesia superior esquerda, tendo sido realizada tomografia computadorizada do crânio e sorologia para toxoplasmose com diagnóstico de neurotoxoplasmose que foi adequadamente tratada.

Persistia com lesão em mucosa nasal francamente ativa, sendo então tratada com $2,5 \mathrm{~g}$ (dose total) de pentamidina, quando apresentou cicatrização completa da lesão. Realizou contagem de carga viral em dezembro de1999: 4.300 cópias por ml, contagem de células CD 205 por $\mathrm{mm}^{3}$; imunofluorescência indireta para LTA: $1 / 40$.

Permanece com infiltração discreta em mucosa nasal, porém asssintomática, em tratamento com zidovudina, lamivudina e nelfinavir. Está em acompanhamento neste serviço há 3 anos.

Caso 4: PCA, 57 anos, masculino, branco, solteiro, natural e procedente de Paracatu, MG. Em agosto de 1998 o paciente apresentou 4 úlceras dolorosas em mucosa oral (em gengiva inferior, mucosa jugal bilateralmente e palato mole).

Concomitante a este quadro apresentou episódio de herpes zoster e referia perda ponderal significativa. Procurou assistência médica há 1 ano, quando a hipótese de AIDS foi sorologicamente confirmada. A carga viral era de 660 cópias por $\mathrm{ml}$ e a contagem de linfócitos CD 4 era de 107 células por $\mathrm{mm}^{3}$ e CD8 de 1384 células por $\mathrm{mm}^{3}$, sendo iniciado tratamento com AZT, ddl e nelfinavir. A investigação para LTA foi realizada, com os seguintes achados: intradermorreação de Montenegro: 15 x 10mm, esfregaço e cultura para leishmania negativos, imunofluorescência indireta de 1/20 e histopatológico: hiperplasia do epitélio, com infiltrado linfoplasmohistiocitário denso em tecido conjuntivo, sem parasitos, característico de processo inflamatório crônico inespecífico. Recebeu tratamento com antimonial pentavalente, $20 \mathrm{mg} \mathrm{SbV/kg/dia,} \mathrm{durante} 22$ dias. A medicação foi suspensa por cardiotoxicidade ( alteração de repolarização no ECG ).

À mesma época apresentou cefaléia holocraniana intensa pulsátil e 4 episódios de convulsões tônicoclônicas, a hipótese diagnóstica de sífilis terciária foi confirmada por exames sorológicos (VDRL 1/64) e liquóricos (FTA-Abs 1/10240). Após tratamento específico, houve regressão do quadro neurológico. Como não houve cicatrização completa das lesões orais, foi novamente tratado com n-metil-glucamina à mesma dose, por 30 dias, desta vez sem intercorrências, apresentando resolução clínica.

Permanece em acompanhamento neste serviço, sem sinais ou sintomas de reativação da LTA. Houve diminuição da carga retroviral, agora 110 cópias por $\mathrm{ml}$, a contagem de células CD4 é de 151 por $\mathrm{mm}^{3} \mathrm{e}$ células CD 8 de 783 por $\mathrm{mm}^{3}$.

\section{DISCUSSÃO}

A co-infecção LTA e AIDS foi descrita recentemente na literatura, deixando lacunas no que se refere ao comportamento clínico e imunológico dos pacientes. Conforme já citado, a manifestação clínica da LTA está intimamente relacionada ao estado de imunidade celular do hospedeiro, principalmente relacionada à resposta imunocelular tipo Th1.

$\mathrm{Na}$ infecção pelo HIV, observa-se progressiva desregulação do sistema imunológico, com desvio da resposta celular tipo Th1 para a humoral tipo Th2, o que é favorável para a replicação e disseminação de organismos intracelulares, como é o caso da leishmania. Os casos descritos referem-se a quatro pacientes com diagnóstico de LTA e HIV, acompanhados de 4 a 37 meses; três deles de difícil resposta terapêutica.

Os pacientes citados, apesar de serem portadores de HIV (três preenchendo o critério de AIDS), não tiveram comportamento clínico e imunológico diante da LTA completamente concordante com o descrito na literatura ${ }^{1}{ }^{8}$ uma vez que apresentavam lesões localizadas, com morbidade moderada, IDR positiva e infiltrado linfoplasmocitário presente na histopatologia. Apenas o paciente de número 1 chegou ao nosso serviço com concomitância de lesão cutânea e mucosa com evolução de apenas 7 meses caracterizando um quadro mais agressivo de LTA, o que também pode ocorrer em imunocompetentes.

Entretanto, em três pacientes, a resposta terapêutica foi insatisfatória em relação ao antimonial pentavalente ( primeira escolha de tratamento), tendo sido a anfotericina B ou a pentamidina as drogas mais eficazes no controle da doença nestes pacientes, o que é observado de maneira geral nas co-infecções de LTA e AIDS $^{9}$. Estes pacientes também costumam apresentar maior taxa de complicações relacionadas ao uso de antimoniais pentavalentes ${ }^{11}$, como ocorreu com três dos quatro pacientes citados (cardiotoxicidade).

O relato desses casos alerta para a diversidade clínica da LTA em pacientes com AIDS. Apesar desta associação ser pouco descrita, provavelmente, com a expansão epidemiológica da AIDS a LTA mais casos de difícil terapêutica serão relatados, com importantes conseqüências sócio-econômicas. 


\section{REFERÊNCIAS BIBLIOGRÁFICAS}

1. Berhe N, Hailu A, Gemetchu T. Human immunodeficiency virus and recurrence of cutaneous leishmaniasis long after healed localized cutaneous leishmaniasis due to Leishmania aethiopica. Transactions of the Royal Society of Tropical Medicine and Hygiene 86: 511-512,1992

2. Bogdan C, Gessner A, Solbach W, Rollinghoff M. Invasion, control and persistence of Leishmania parasites. Current Opinion in Immunology 8: 517-525, 1996.

3. Coura JR, Castro GB, Grimaldi Jr G. Disseminated American Cutaneous Leishmaniasis in a Patient with AIDS. Memórias do Instituto Oswaldo Cruz 82: 581-582, 1987.

4. Da Cruz AM, Machado ES, Menezes JA, Rutowitsch M, Coutinho SG. Cellular and humoral immune responses of a patient with American cutaneous leishmaniasis and AIDS. Transactions of the Royal Society of Tropical Medicine and Hygiene 86 : 511$512,1992$.

5. Da Cruz AM, Mattos M, Oliveira N, Coutinho Z, Filgueiras D, Machado E, Mayrink W, De Luca PM, Mendonça SCF, Coutinho SG. Cellular Immune responses to Leishmania brasiliensis in Patients with AIDS Associated to American Tegumentary Leishmaniasis. In: Resumos da XV Reunião Anual de Pesquisa Aplicada em Doenças de Chagas e III Reunião de Pesquisa
Aplicada em Leishmaniose. Revista da Sociedade Brasileira de Medicina Tropical 32 (supl II ) p. 97-98, 1999.

6. Daudén E, Penãs PF, Rios L, Jimenez M, Fraga J, Alvar J, Diez A. Leishmaniasis presenting as a dermatomyositis- like eruption in AIDS. Journal of American Academy of Dermatology 35: 316-319, 1996

7. Fauci AS. Host factors and the pathogenesis of HIV - induced disease. Nature 384: 529-534, 1996.

8. Górgolas M, Castrillo JM , Guerrero MF. Visceral Leishmaniasis in Patients with AIDS: Report of Three Cases Treated with Pentavalent Antimony and Interferon - Gama. Clinical Infectious Disease 17: 57-58, 1993.

9. Moritomo AA, Pontello R, Eisele RL, Morimoto HK, Bortoliero AL. LTA difusa em paciente infectado pelo HIV: relato de caso. Anais Brasileiros de Dermatologia 73: 219-222, 1998.

10. Olliaro PL, Bryceson AM. Practical Progress and New Drugs for Changing Patterns of Leishmaniasis. Parasitology Today 9: 323- 328, 1993.

11. Wolday D, Berhe N, Akuffo H, Britton S. Leishmania - HIV Interaction: Immunopathogenic Mechanisms. Parasitology Today 15: 182-186, 1999. 